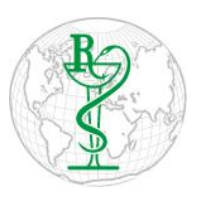

INDO GLOBAL JOURNAL OF

PHARMACEUTICAL SCIENCES

ISSN 2249- 1023

\title{
In Vitro Antioxidant Potential of Polyherbal Formulation of Three Different Herbal Drugs
}

\author{
Arun Kumar ${ }^{1,2^{*}}$, A.N. Kalia ${ }^{2}$, Harsimran Singh ${ }^{3}$ \\ ${ }^{1}$ Department of RIC, I.K.G. Punjab Technical University, Kapurthala-144601, Punjab, India. \\ ${ }^{2}$ Department of Pharmacognosy, Sri Sai College of Pharmacy, Pathankot, Punjab, India. \\ ${ }^{3}$ Department of Pharmacology, Sri Sai College of Pharmacy, Pathankot, Punjab, India.
}

Address for Correspondence: Arun Kumar, arunbeh185@gmail.com

\begin{tabular}{l} 
Received: \\
18.01.2020 \\
Accepted: \\
30.04 .2020 \\
Published: \\
20.12 .2020 \\
Keywords \\
Antioxidant, \\
Momordica \\
charantia, \\
Andrographis \\
paniculata, \\
Withania \\
somnifera. \\
\hline
\end{tabular}

Received:

18.01.2020

Accepted:

30.04.2020

Published:

Keywords

Antioxidant,

Momordica

somnifera.

\begin{abstract}
The present study aimed to investigate the antioxidant activity of a polyherbal formulation containing three medicinal plants \{Momordica charantia (MC), Andrographis paniculata (AP) and Withania somnifera (WS)\}, well known in Ayurveda for their role in various therapeutical activities. Ethanolic extract of each herbal drug was prepared by the Soxhlation process. Phytochemical constituents, total phenolic content (TPC) and total flavonoid content (TFC) of the extracts were estimated. Extracts were analyzed for its antioxidant potential by DPPH (1, 1-diphenyl-2-picrylhydrazil) and ABTS $\{2,2$ '-azino-bis (3ethylbenzothiazoline-6-sulfonic acid)\} free scavenging assay. Our results showed that all the extracts possessed high antioxidant activity individually and even showed more potential in different ratio combinations as compared to Ascorbic acid. $\mathrm{IC}_{50}$ values of drug combination (MC:AP:WS) the ratio (2:2:1) exhibited higher antioxidant potential in DPPH $(26.40 \pm 0.56 \mu \mathrm{g} / \mathrm{mL})$ and ABTS $(28.91 \pm 0.34 \mu \mathrm{g} / \mathrm{mL})$, which may be due to synergistic effect of polyherbal formulation with higher phenolic and flavonoid content. () 2020 iGlobal Research and Publishing Foundation. All rights reserved.
\end{abstract}

Cite this article as: Kumar, A.; Kalia, A.N.; Singh, H. In vitro antioxidant potential of polyherbal formulation of three different herbal drugs. Indo Global J. Pharm. Sci., 2020; 10(4): 70-76. DOI: http://doi.org/10.35652/IGJPS.2020.104010.

\section{INTRODUCTION}

Plants have always been a major source of medicines, either in the form of traditional preparations or as pure active molecules [1]. Herbal drugs are in demand worldwide in primary health care due to their efficacy, safety and lesser side effects. Plants contain numerous phytochemicals with different bioactivities such as antioxidants, anti-inflammatory, antidiabetic and anticancer activities [2].

Plants are the potential source of natural antioxidants. Antioxidants are molecules that inhibit harmful free radicals and reactive oxygen species (ROS) and delay or inhibit cellular damage [3]. ROS including superoxide radicals, hydrogen peroxide, hydroxyl radicals and singlet oxygen are generated as byproducts of normal metabolisms [4]. Accumulation of ROS, results in a high level of free radicals in the body which causes oxidative stress [5]. Oxidative stress is associated in the development of various pathological conditions such as cancer, cardiovascular disorders, neurodegenerative disorders, diabetes mellitus, etc. [6]. Diabetes is associated with a high level of free radicals and many plants show antihyperglycemic property attributed to their antioxidant potential [7]. The remedial effects of several medicinal plants are usually due to antioxidant phytochemicals present in it such as polyphenols, flavonoids and phenolic compounds [8]. Further, these phytochemicals have many favorable effects on health, such as inhibition of low-density protein oxidization, anti-inflammatory, anti-carcinogenic properties, antidiabetic activity and are well known to function as chemo-preventive agents against oxidative damage by counteracting the deleterious effects of ROS [9].

Hydroalcoholic extracts of three drugs i.e. Momordica charantia (MC), Andrographis paniculata (AP) and Withania 


\section{Indo Global Journal of Pharmaceutical Sciences, 2020; 10(4): 70-76}

somnifera (WS) were prepared using soxhlation method for the study because these three plants have been used since ancient times in the Ayurvedic system of medicine for the treatment of numerous ailments. The numerous studies revealed that these herbs exhibit antioxidant potential. In this study polyherbal drug has been prepared by mixing these extracts (lyophilized) in different ratios as (MC:AP:WS) like $(1: 1: 1), \quad(2: 1: 2)$ and $(2: 2: 1)$. This is a new polyherbal formulation that has not been evaluated until now although it is likely to exhibit synergistic and significant antioxidant potential.

Momordica charantia (Karela) also known as bitter melon, is a member of the cucumber family (Cucurbitaceae). The fruit of Momordica charantia contains phytoconstituents like saponins, alkaloids, polysaccharides, resins, phenolic constituents, protein and steroids [10]. Additionally, Momodica charantia consists of chemical constituents like charantin, charine, cryptoxanthin, cucurbitins, diosgenin, hydroxytryptamines, lanosterol, oleanolic acid, oleic acid, lutein, lycopene, steroidal glycosides, stigmasterol, vacine, zeatin, zeaxanthin, etc. [11]. Fruits and seeds of bitter melon have scientifically proven for antidiabetic [12], cholesterollowering effect [13], antioxidant properties [14, 15], antiinflammatory [16] and anti-cancer activity [17].

Andrographis paniculata (Kalmegh) belongs to the family Acanthaceae, commonly known as King of Bitters, is an annual, branched, erect herb running half to one meter in height [18]. It has shown to possess wide spectrum of pharmacological properties like anticancer [19], antiinflammatory [20], antioxidant [21], immunostimulant [22] and antihyperglycemic [23]. Chemical constituents like diterpenes, lactone and flavonoids in the plant are responsible for pharmacological activities. Four lactones Chuaxinlian A (deoxyandrographolide), B (andrographolide), C (neoandrographolide) and D (14-deoxy-11, 12didehydroandrographolide) were isolated from the aerial parts [24]. The leaf and stem extracts were reported for the presence of glycosides, flavonoids, steroids, terpenoids, tannins, saponins and phenolic compounds [25].

Withania somnifera (Ashwagandha) is a green shrub from Solanaceae family. Its roots are potential source of antioxidant, antihyperglycemic, hypo-cholesterolemic [26] and immunomodulatory agents [27]. The roots are reported to contain alkaloids like somniferine, somnine, somniferinine, withananine, pseudo-withanine, tropine, pseudo-tropine, anferine and anhydrine. Two acyl steryl glucoside, sitoindoside VII and sitoindoside VIII have been isolated from roots. The other constituents are amino acids, steroids, volatile oil, starch, reducing sugars, glycosides, hentriacontane, dulcitol, withaniol, etc. [28].

The objective of the study is to assess the antioxidant potential of different combination ratios of polyherbal formulation and to find an optimized ratio to explore its application on other complications like diabetes.

\section{MATERIALS AND METHODS}

\section{Plant Material}

The dried fruits of Momordica charantia, whole plant of Andrographis paniculata and roots of Withania somnifera were purchased from crude drug supplier Herb Heal Consortium Pvt. Ltd., Ramtirath Road, Amritsar, Punjab and crude drugs were authenticated by Dr. Bikarma Singh, Herbarium \& Crude Drug Repository Division, CSIR-IIIM, Canal Road, Jammu.

\section{Extraction and Lyophilization}

The selected plants materials were shade dried, coarsely powdered and subjected to extraction in $80 \%$ ethanol in Soxhlet apparatus. These hydro-alcohol extracts were concentrated under vacuum using rotary evaporator. These concentrated extracts were freeze dried at $-20^{\circ} \mathrm{C}$ for overnight and were lyophilized. The obtained lyophilized extracts were stored in an airtight container and kept in the desiccator till used.

\section{Phytochemical Screening}

Ethanolic extracts (80\%) of different plant parts were screened for various phytoconstituents such as carbohydrates, alkaloids, glycosides, phenolic compounds, flavonoids, steroids, triterpenoids and saponins [29, 30].

\section{Estimation of Total Phenolic Content}

Gallic acid standard solution was prepared by dissolving 10 $\mathrm{mg}$ of gallic acid in $100 \mathrm{ml}$ of methanol $(50 \%)$ to prepare the stock solution $(100 \mu \mathrm{g} / \mathrm{mL})$ and further diluted to $10,20,40$, $60,80,100 \mu \mathrm{g} / \mathrm{mL}$. Test samples and various concentrations of the standard $(1 \mathrm{ml}$ each) were taken in test tubes, diluted with $10 \mathrm{ml}$ of distilled water, $1.5 \mathrm{ml}$ of Folin-Ciocalteu' reagent was introduced to the tubes and was kept at room temperature for $5 \mathrm{~min}$. Then, $4 \mathrm{ml}$ of $20 \%$ (w/v) $\mathrm{Na}_{2} \mathrm{CO}_{3}$ solution was added and the final volume was made up to 25 $\mathrm{ml}$ with distilled water. It was allowed to stand for $30 \mathrm{~min}$ at room temperature. Absorbance was measured at $765 \mathrm{~nm}$ using a UV-Visible spectrophotometer (Shimadzu, Japan). Quantification was done based on standard curve of gallic acid. Results were expressed as gallic acid equivalents (GAE) $\% \mathrm{w} / \mathrm{w}[31]$. 


\section{Indo Global Journal of Pharmaceutical Sciences, 2020; 10(4): 70-76}

Total Phenolic Contents $(\%)=$ GAE $\times V \times D \times 10^{-6} \times 100 / \mathrm{W}$

Where, GAE - Gallic acid equivalent $(\mu \mathrm{g} / \mathrm{ml}) ; \mathrm{V}$ - Total volume of sample (ml); D - Dilution factor, W - Sample weight $(\mathrm{g})$.

\section{Estimation of Total Flavonoid Content}

$10 \mathrm{mg}$ of rutin was dissolved in $100 \mathrm{ml}$ of $80 \%$ methanol (100 $\mu \mathrm{g} / \mathrm{mL})$. Further dilutions of rutin $(10,20,40,60,80$ and 100 $\mu \mathrm{g} / \mathrm{mL}$ ) were prepared by serial dilution of stock solution. Stock solution $(10 \mathrm{mg} / \mathrm{ml})$ of extracts was prepared separately. Samples and various concentrations of standard $(0.5 \mathrm{ml}$ each $)$ were mixed with $1.5 \mathrm{ml}$ of $95 \%$ methanol separately. $0.1 \mathrm{ml}$ of $10 \%$ aluminium chloride, $0.1 \mathrm{ml}$ of $1 \mathrm{M}$ potassium acetate and $2.8 \mathrm{ml}$ of distilled water were added. After incubation at normal temperature for $30 \mathrm{~min}$, the absorbance of the reaction mixture was measured at $415 \mathrm{~nm}$ with UV-Visible spectrophotometer. Quantification was done based on standard curve of rutin. Results were expressed as rutin equivalents (RE) $(\% \mathrm{w} / \mathrm{w})[32]$.

Flavonoid Content $(\%)=\mathbf{R E} \times \mathrm{V} \times \mathrm{D} \times 10^{-6} \times 100 / \mathrm{W}$

Where, RE - Rutin equivalent $(\mu \mathrm{g} / \mathrm{mL}) ; \mathrm{V}$ - Total volume of sample (ml); D - Dilution factor; W - Sample weight (g)

\section{In Vitro Antioxidant Studies}

All the extracts and their different combination proportions were tested for their free radical scavenging property using different in vitro models. All experiments were performed thrice. Ascorbic acid was used as standard control in each experiment. Results were expressed in $\mathrm{IC}_{50}$ values.

\section{DPPH radical scavenging activity}

DPPH (1, 1-diphenyl-2-picrylhydrazyl) is a stable free radical. The working solutions $(10,20,40,60,80,100 \mu \mathrm{g} / \mathrm{mL})$ of individual extracts and its combinations were prepared in methanol. Ascorbic acid was taken as positive control. $1 \mathrm{ml}$ of DPPH solution ( $0.1 \mathrm{mM}$ in methanol) was mixed with $3 \mathrm{ml}$ of sample extracts and standard solution separately. The mixture was shaken and kept for 30 minutes in the incubator. Absorbance was measured spectrophotometrically at $517 \mathrm{~nm}$.

The DPPH radical scavenging activity was calculated using the following formula:

\section{DPPH radical scavenging activity $(\%$ Inhibition $)=\left[\left(\mathrm{A}_{0}-\right.\right.$} $\left.\left.\mathrm{A}_{1} / \mathrm{A}_{0}\right)\right] \times 100$

Where $A_{0}$ is the absorbance of the blank and $A_{1}$ is the absorbance of extract mixed with DPPH.
IC $_{50}$ value (inhibitory concentration of agent at which it scavenged $50 \%$ of DPPH) was obtained by interpolation from linear regression analysis [33].

\section{Antioxidant activity by ABTS Assay}

ABTS $\left\{2,2^{\prime}\right.$-azino-bis(3-ethylbenzothiazoline-6-sulfonic acid) \} solution was prepared by dissolving light green colored ABTS in distilled water to reach the final concentration of $7.4 \mathrm{mM} ; 2.46 \mathrm{mM}$ potassium persulfate solution was also prepared. Then ABTS stock solution was prepared by mixing the two solutions in ratio 1:1 and keeping the solution in dark for 24 hours. The working solution of ABTS was prepared by diluting the solution in methanol in ratio 1:25. The extracts were prepared in DMSO (Dimethyl sulfoxide) at $1 \mathrm{mg} / \mathrm{ml}$ concentration. Ascorbic acid was taken as standard drug and methanol was used as blank. A solution containing methanol and ABTS solution was taken for background absorbance and DMSO was used as negative control.

To $200 \mu \mathrm{l}$ of ABTS solution, extracts were added at the different concentrations $(10,20,40,60,80$ and $100 \mu \mathrm{g} / \mathrm{mL})$ and mixed properly for 30 seconds. The absorbance was read at $734 \mathrm{~nm}$. The discoloration of the sample was plotted against the sample concentration in order to calculate the $\mathrm{IC}_{50}$ value [34].

\section{RESULTS AND DISCUSSION}

\section{Yield of Extracts}

Percentage yield of three different $80 \%$ ethanolic extracts were obtained as Momordica charantia $(12.54 \%$ w/w), Andrographis paniculata $(8.48 \% \mathrm{w} / \mathrm{w})$ and Withania somnifera $(10.45 \% \mathrm{w} / \mathrm{w})$.

\section{Phytochemical Screening of the Plant Extracts}

The preliminary phytochemical screening of $80 \%$ ethanolic extracts of three different plants revealed the presence of carbohydrates, alkaloids, glycosides, phenolic compounds, flavonoids, saponins, triterpenoids and steroids.

\section{Total Phenolic Content}

$80 \%$ ethanolic extracts of Momordica charantia, Andrographis paniculata and Withania somnifera were determined for its total phenolic content based on its gallic acid equivalent Folin-Ciocalteu assay. The amount of gallic acid equivalent was determined from the calibration curve of gallic acid (Figure 1). Results were expressed as percent w/w in Table 1. 
tested have higher scavenging activity and at the concentration of $100 \mu \mathrm{g} / \mathrm{mL}$, the scavenging activity of all the extracts

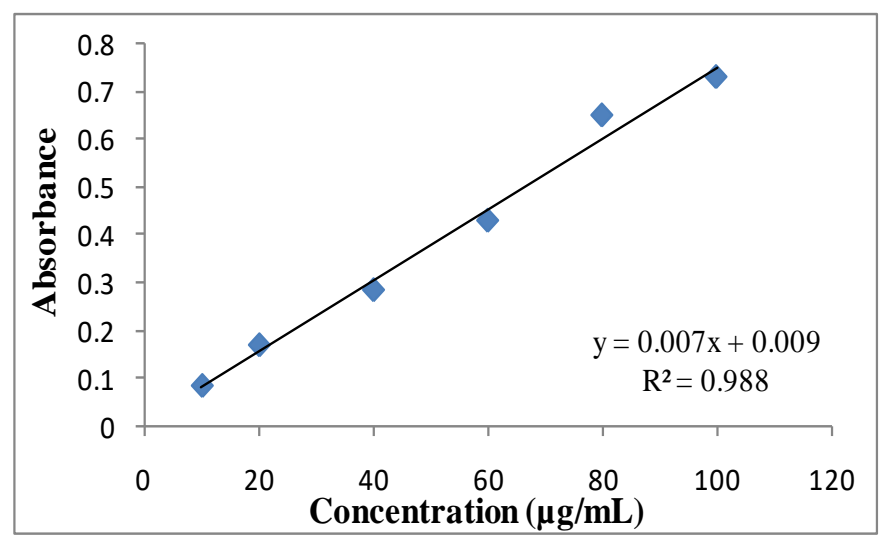

Figure 1: Standard Graph of Gallic Acid

\section{Total Flavonoid Content}

Extracts of Momordica charantia, Andrographis paniculata and Withania somnifera were determined for its total flavonoids content based on its rutin equivalent aluminium chloride assay. The amount of rutin equivalent was determined from the calibration curve of rutin (Figure 2). Results were expressed as percent $\mathrm{w} / \mathrm{w}$ in Table 1.

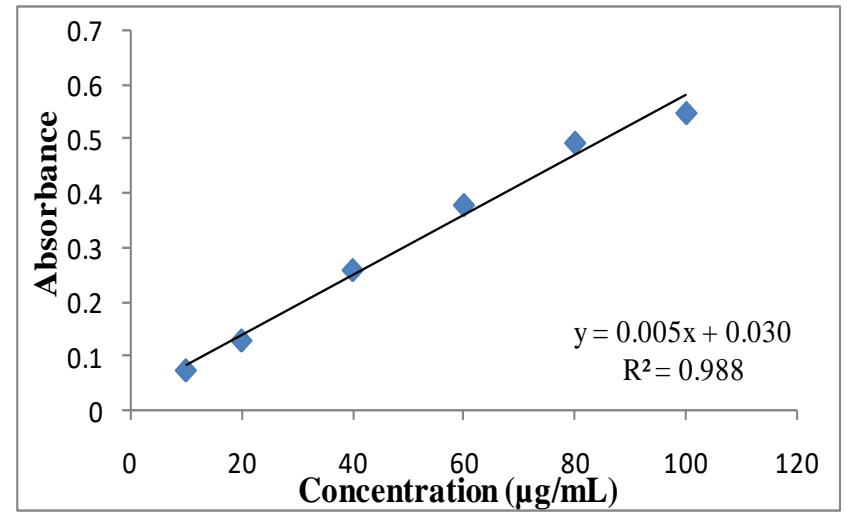

Figure 2: Standard Graph of Rutin

\begin{tabular}{|l|l|l|}
\hline Extracts & $\begin{array}{l}\text { Total phenol } \\
\text { content } \mathbf{( \% \mathbf { w } / \mathbf { w } )} \\
\text { Mean } \pm \text { SD }\end{array}$ & $\begin{array}{l}\text { Total flavonoid } \\
\text { content (\% w/w) } \\
\text { Mean } \pm \text { SD }\end{array}$ \\
\hline $\begin{array}{l}\text { Momordica } \\
\text { charantia }\end{array}$ & $3.53 \pm 0.75$ & $0.25 \pm 1.20$ \\
\hline $\begin{array}{l}\text { Andrographis } \\
\text { paniculata }\end{array}$ & $5.42 \pm 0.48$ & $0.80 \pm 0.65$ \\
\hline Withania somnifera & $4.10 \pm 1.74$ & $0.55 \pm 0.58$ \\
\hline
\end{tabular}

Table 1: Total phenolic content and total flavonoid content of the different extracts. Data are expressed as mean value

$$
\pm \mathrm{SD}(\mathrm{n}=3)
$$

\section{DPPH radical scavenging activity}

The antiradical activity of the extracts was measured by ability to scavenge DPPH free radicals and was compared with standard Ascorbic acid. It was observed that all the extracts reached from 61.6 to $93.7 \%$ presented in Figure 3. IC $_{50}$ Values for different samples in DPPH assay are presented in Table 2.

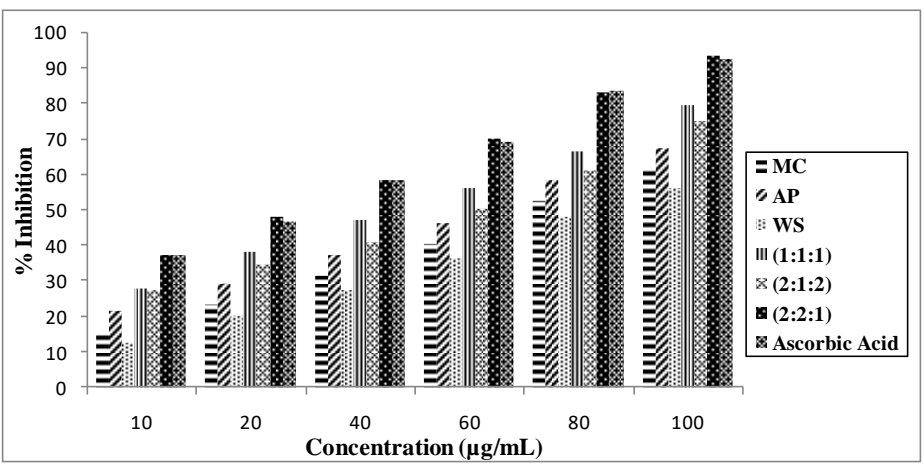

Figure 3: DPPH radical scavenging effects of different plant extracts and ascorbic acid

\begin{tabular}{|l|l|}
\hline Extracts & $\mathbf{I C}_{\mathbf{5 0}}(\boldsymbol{\mu \mathbf { g }} / \mathbf{m L})$ \\
\hline Momordica charantia & $76.57 \pm 0.96$ \\
\hline Andrographis paniculata & $64.84 \pm 0.67$ \\
\hline Withania somnifera & $85.98 \pm 0.75$ \\
\hline Ratio (1:1:1) & $46.59 \pm 0.23$ \\
\hline Ratio (2:1:2) & $54.72 \pm 0.93$ \\
\hline Ratio (2:2:1) & $26.40 \pm 0.56$ \\
\hline Ascorbic acid & $27.29 \pm 0.45$ \\
\hline
\end{tabular}

Table 2: Comparison of $\mathrm{IC}_{50}$ of different samples for study in DPPH assay. Data are expressed as mean value \pm SD $(\mathbf{n}=\mathbf{3})$

ABTS radical scavenging activity

The antiradical activity of the extracts was measured by the ability to scavenge ABTS free radicals and was compared with standard Ascorbic acid. It was observed that all the extracts tested have higher scavenging activity and at the concentration of $100 \mu \mathrm{g} / \mathrm{mL}$, the scavenging activity of all the extracts reached from 57.6 to $91 \%$ presented in Figure 4. IC $_{50}$ Values for different samples in ABTS assay are presented in Table 3.

\begin{tabular}{|l|l|}
\hline Extracts & $\mathbf{I C}_{\mathbf{5 0}}(\boldsymbol{\mu} \mathbf{g} / \mathbf{m L})$ \\
\hline Momordica charantia & $84.26 \pm 0.96$ \\
\hline Andrographis paniculata & $69.02 \pm 0.45$ \\
\hline Withania somnifera & $91.47 \pm 0.88$ \\
\hline Ratio (1:1:1) & $52.93 \pm 0.65$ \\
\hline Ratio (2:1:2) & $59.64 \pm 0.44$ \\
\hline Ratio (2:2:1) & $28.91 \pm 0.34$ \\
\hline Ascorbic acid & $31.20 \pm 0.25$ \\
\hline
\end{tabular}

Table 3: Comparison of $\mathrm{IC}_{50}$ values of different samples for study in ABTS assay. Data are expressed as mean value \pm SD $(n=3)$ 
Indo Global Journal of Pharmaceutical Sciences, 2020; 10(4): 70-76

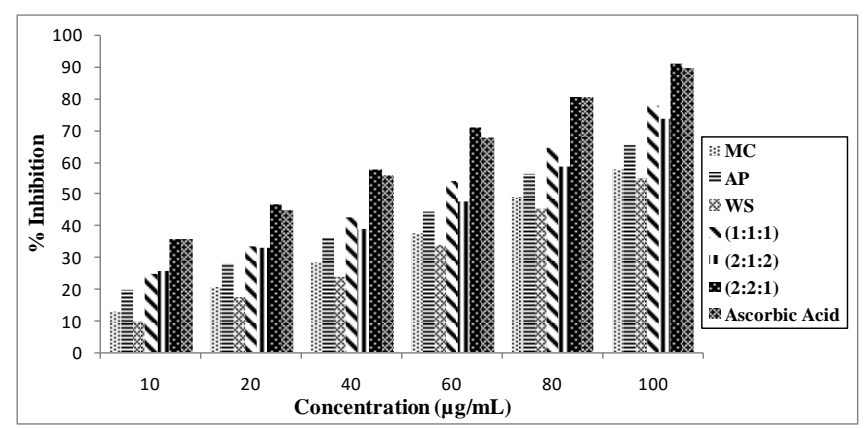

Figure 4: ABTS scavenging activity of different extracts, their combinations and ascorbic acid.

The results of present study confirmed the antioxidant effect of $80 \%$ ethanolic extract of Momordica charantia, Andrographis paniculata and Withania somnifera in different combinations by DPPH free radical scavenging and ABTS assay method. The findings also suggest that (MC:AP:WS) at ratio $(2: 2: 1)$ is most potent antioxidant agent indicated by its low $\mathrm{IC}_{50}$ value.

In a normal cell, there is an appropriate balance between free radicals and antioxidants. However, this balance can be shifted towards free radicals when the production of oxygen species is increased or when the antioxidants level is declined. This state is 'oxidative stress' and can lead to serious cell damage if stress is massive or prolonged [35, 36]. Oxidative stress plays a major role in degenerative or pathological processes, such as diabetes mellitus, hypertension, cancers, heart failure, neurodegenerative disorders, etc $[37,38]$.

Antioxidants from natural sources have attracted considerable attention from researchers and users on account of adverse toxicological reports of some synthetic antioxidants. In this context, medicinal plants are considered safer, cost-effective and cure the disease from its root cause [39]. Among these, medicinal plants are being viewed as an easily available and potent source of antioxidants as they contain a mixture of numerous different chemical compounds that may act individually or in synergy to cure disease and improve health [40].

In the majority of traditional systems like Ayurveda, Unani system, Chinese system of medicine, etc., many diseases are better managed by herbs combination (Polyherbal) instead of single herb because of synergism and fewer side effects [41]. The concept of polyherbalism has been mentioned in Sharangdhar Samhita, an Ayurvedic literature dating back to 1300 AD [42]. Polyherbal formulations magnify the therapeutic action and reduce the concentrations of single herbs, thereby reducing the adverse effects.
In this study, $80 \%$ ethanolic extracts of three crude drugs Momordica charantia, Andrographis paniculata and Withania somnifera were prepared. Phytochemical study of each extract revealed the presence of glycosides, alkaloids, flavonoids, steroids, phenolic compounds and saponins. For each extract, total phenolic content was calculated as $3.53 \pm 0.75,5.42 \pm 0.48$ and $4.10 \pm 1.74$ respectively, (expressed as GAE \% w/w). Similarly for each extract, total flavonoid content was calculated as $0.25 \pm 1.20, \quad 0.80 \pm 0.65$ and $0.55 \pm 0.58$ respectively, (expressed as RE \% w/w). The results obtained demonstrated that all the three extracts of Momordica charantia, Andrographis paniculata and Withania somnifera have significant amount of TPC and TFC.

All the extracts were evaluated individually as well as in their three different combination ratio as (MC:AP:WS) i.e. (1:1:1), (2:1:2) and (2:2:1) for the antioxidant activity at different concentration of $(10,20,40,60,80$ and $100 \mu \mathrm{g} / \mathrm{mL})$ and it is reported in our study that all the samples possessed free radical scavenging activity in concentration dependent manner.

Individual extracts of the drugs show antioxidant potential comparable to Ascorbic acid but in combination action got boosted dramatically. $\mathrm{IC}_{50}$ value for combination ratio $(2: 2: 1)$ of crude drugs was found to be $26.40 \pm 0.56$, whereas for ascorbic acid it is $27.29 \pm 0.45$ in DPPH free radical scavenging method. $\mathrm{IC}_{50}$ value of same sample was found to be $28.91 \pm 0.34$, whereas for ascorbic acid it is $31.20 \pm 0.25$ in ABTS assay. Based on $\mathrm{IC}_{50}$ values combination (MC:AP:WS) at ratio (2:2:1) indicated marked antioxidant activity than the standard drug ascorbic acid.

\section{CONCLUSION}

The present study showed the significant antioxidant potential of polyherbal formulation of three herbal drugs in DPPH and ABTS in-vitro models as compared to Ascorbic acid as standard indicating synergistic effect of phytochemicals present in the extracts. The ratio (MC:AP:WS) $(2: 2: 1)$ showed maximum antioxidant potential than standard drug Ascorbic acid. From these results, it can be concluded that these herbal extracts in combination might be helpful in preventing or slowing the progress of various oxidative stress-related diseases related to gastro intestinal tract and diabetes.

\section{CONFLICTS OF INTEREST}

The authors declare that there is no conflict of interest regarding the publication of this paper. 


\section{Indo Global Journal of Pharmaceutical Sciences, 2020; 10(4): 70-76}

\section{ACKNOWLEDGEMENT}

I wish to acknowledge my thanks to Sri Sai College of Pharmacy, Pathankot and IIIM, Jammu (J\&K) for providing place of work and Department of RIC, I.K. Gujral Punjab Technical University, Kapurthala for their technical support. Authors also acknowledge Prof. (Dr.) Girish Kumar Gupta, Director Research and Development, Sri Sai Group of Institutes, Badhani, Pathankot for his valuable suggestions and advice.

\section{DATA AVAILABILITY}

Not declared.

\section{FUNDING SOURCE}

Not declared

\section{REFERENCES}

1. Gill, N.S., Bajwa, J., Sharma, P., Dhiman, K., Sood, S. Evaluation of antioxidant and antiulcer activity of traditionally consumed cucumis melo seeds. J. Pharmacol. Toxicol., 2011; 6(1): 82-89.

2. Kalia, A.N. Text book of Industrial Pharmacognosy, 1st ed.; CBS Publishers: New Delhi, 2005.

3. Poonia, P., Niazi, J., Chaudhary, G., Kalia, A.N. In vitro antioxidant potential of Jasminum mesnyi Hance (leaves) extracts. Res. J. Pharm. Biol. Chem. Sci., 2011; 2(1): 348-57.

4. Wang, S.Y., Jiao, H. Scavenging capacity of berry crops on superoxide radicals, hydrogen peroxide, hydroxyl radicals and singlet oxygen. J. Agric. Food Chem., 2000; 48 (11): 5677-84.

5. Sreeramulu, D., Reddy, C.V.K., Chauhan, A., Balakrishna, N., Raghunath, M. Natural antioxidant activity of commonly consumed plant foods in India: effect of domestic processing. Oxid. Med. Cell. Longev., 2013: 1-12.

6. Sen, S., Chakraborty, R., Sridhar, C., Reddy, Y.S.R., De, B. Free radicals, current status and future prospect. Int. J. Pharma. Sci. Rev. Res., 2010; 3: 91-100.

7. Borar, S., Punia, P., Kalia, A.N. Antioxidant potential of nbutanol fraction from extract of Jasminum mesnyi Hance leaves. Indian J. Exp. Biol., 2011; 49: 39-43.

8. Mukhija, M., Singh, M.P., Dhar, K.L., Kalia, A.N. Cytotoxic and antioxidant activity of Zanthoxylum alatum stem bark and its flavonoid constituents. J. Pharmacogn. Phytochem., 2015; 4(4): 86-92.

9. Miyake, K., Mickley, L., Litman, T., Zhan, Z., Robey, R., Cristensen, B., Brangi, M., Greenberger, L., Dean, M., Fojo, T., Bates, S.E. Molecular cloning of cDNAs which are highly overexpressed in mitoxantrone-resistant cells: Demonstration of homology to ABC transport genes. Cancer Res., 1999; 59 (1): 8-13.
10. Jia, S., Shen, M., Zhang, F., Xie, J. Recent advances in Momordica charantia: functional components and biological activities. Int. J. Mol. Sci., 2017; 18(12): E2555.

11. Aswar, P.B., Kuchekar, B.S. Phytochemical, microscopic, antidiabetic, biochemical and histopathological evaluation of Momordica charantia fruits. Int. J. Pharm. Sci., 2000; 4(1): 325-331.

12. Wang, Q., Wu, X., Shi, F., Liu, Y. Comparison of antidiabetic effects of saponins and polysaccharides from Momordica Charantia L. in STZ-induced type 2 diabetic mice. Biomed. Pharmacother., 2019; 109:744-750.

13. Tan, M.J., Ye, J.M., Tumer, N., Hohnen-Behrens, C., Ke, C.Q., Tang, C.P., Chen, T., Weiss, H.C., Gesing, E.R., Rowland, A., James, D.E., Ye, Y. Antidiabetic activities of triterpenoids isolated from bitter melon associated with activation of the AMPK Pathway. Chem. Biol., 2008; 15(3): 263-273.

14. Ghous, T., Aziz, N., Mehmood, Z., Andleeb, S. Comparative study of antioxidant, metal chelating and antiglycation activities of Momordica charantia flesh and pulp fraction. Pak. J. Pharm., 2015; 28: 1217-1223.

15. Panda, B.C., Mondal, S., Devi, K.S., Maiti, T.K., Khatua, S., Acharya, K., Islam, S.S. Pectic polysaccharide from the green fruits of Momordica charantia (Karela): structural characterization and study of immunoenhancing and antioxidant properties. Carbohydr. Res., 2015; 401: 24-31.

16. Liaw, C.C., Huang, H.C., Hsiao, P.C., Zhang, L.J., Lin, Z.H., Hwang, S.Y., Hsu, F.L., Kuo, Y.H. 5 $\beta$, 19-epoxycucurbitane triterpenoids from Momordica charantia and their antiinflammatory and cytotoxic activity. Planta. Med., 2015; 81: 62-70.

17. Raina, K., Kumar, D., Agarwal, R. Promise of bitter melon (Momordica charantia) bioactives in cancer prevention and therapy. Semin. Cancer. Biol., 2016; 40-41: 116-129.

18. Latto, S.K., Khan, S., Dhar, A.K., Chaudhry, D.K., Gupta, K.K., Sharma, P.R. Genetics and mechanism of induced male sterility in Andrographis paniculata (Berm.f.) Nees and its Significance. Curr. Sci., 2006; 91(4): 515-519.

19. Chao, C.Y., Lii, C.K., Hsu, Y.T., Lu, C.Y., Liu, K.L., Li, C.C., Chen, H.W. Induction of heme oxygenase-1 and inhibition of TPA-induced matrix metalloproteinase-9 expression by andrographolide in MCF-7 human breast cancer cells. Carcinogenesis., 2013; 34: 1843-1851.

20. Yu, A.L., Lu, C.Y., Wang, T.S., Tsai, C,W., Liu, K.L., Cheng, Y.P., Chang, H.C., Lii, C.K., Chen, H.W. Induction of heme oxygenase 1 and inhibition of tumor necrosis factor alphainduced intercellular adhesion molecule expression by andrographolide in EA.hy926 cells. J. Agric. Food Chem., 2010; 58: 7641-7648.

21. Lu, C.Y., Yang, Y.C., Li, C.C., Liu, K.L., Lii, C.K., Chen, H.W. Andrographolide inhibits TNF alpha- induced ICAM-1 


\section{Indo Global Journal of Pharmaceutical Sciences, 2020; 10(4): 70-76}

expression via suppression of NADPH oxidase activation and induction of HO-1 and GCLM expression through the PI3K/Akt/Nrf2 and PI3K/Akt/AP-1 pathways in human endothelial cells. Biochem. Pharmacol., 2014; 91: 40-50.

22. Calabrese, C., Berman, S.H., Babish, J.G., Ma, X., Shinto, L., Dorr, M., Wells, K., Wenner, C.A., Standish, L.J. A phase I trial of andrographolide in HIV positive patients and normal volunteers. Phytother. Res., 2000; 14: 333-338.

23. Yu, B.C., Hung, C.R., Chen, W.C., Cheng, J.T. Antihyperglycemic effect of andrographolide in streptozotocin-induced diabetic rats. Planta Medica., 2003; 69: 1075-1079.

24. Das, P., Srivastav, A.K. Phytochemical extraction and characterization of the leaves of Andrographis paniculata for its anti-bacterial, anti-oxidant, anti-pyretic and anti-diabetic activity. Int. J. Inn. Res. Sci. Eng. Tech., 2014; 3(8): 1517684.

25. Goodman, S.L., Gilman, A. The pharmacological basis of therapeutics, 9th ed.; Macmillan Publishing Co Inc: New York, 2000; 959-975.

26. Andallu, B., Radhika, B. Hypoglycemic, diuretic and hypocholesterolemic effect of winter cherry (Withania somnifera, Dunal) root. Indian J. Exp. Biol., 2000; 38(6): 607609.

27. Ziauddin, M., Phansalkar, N., Patki, P., Diwanay, S., Patwardhan, B., Studies on the immunomodulatory effects of Ashwagandha. J. Ethnopharmaco., 1996; 50: 69-76

28. Deshpande, D.J. A Handbook of Herbal Remedies. Agrobios: India, 2008; 48-51.

29. Kokate, C.K., Purohit, A.P., Gokhale, S.B. Pharmacognosy. Nirali Prakashan: India, 2007; 138-40.

30. Trease, G,E., Evans, W,C. Pharmacognosy, 16th ed.; Saunders, London, 1994; 177-80.

31. Madaan, R., Bansal, G., Kumar, S., Sharma, A. Estimation of total phenols and flavonoids in extracts of Actaea spicata roots and antioxidant activity studies. Indian J. Pharm. Sci., 2011; 73: 666-669.

32. Chang, C.C., Yang, M.H., Wen, H. M., Chern, J.C. Estimation of total flavonoids content in propolis by two complementary colorimetric methods. J. Food Drug Anal., 2002; 10, 178-182.

33. Alam, M.N., Bristi, N.J., Rafiquzzaman, M. Review on in vivo and in vitro methods evaluation of antioxidant activity. Saudi Pharma. J., 2013; 21: 143-152.
34. Thaipong, K., Boonprakob, U., Crosby, K., Zevallos, L.C., Byrne, D.H. Comparison of ABTS, DPPH, FRAP, and ORAC assays for estimating antioxidant activity from guava fruit extracts. J. Food Compos. Anal., 2006; 19, 669-675.

35. Singh, H., Sidhu, S., Khan, M.U. Free radical scavenging property of $\beta$-Aescin and Trans- chalcone: In Vitro study. Eur. J. Pharm. Med. Res., 2016; 3(2): 309-312.

36. Panchawat, S., Rathore, K.S., Sisodia, S.S. A review on herbal antioxidants. Inter. J. Pharmtech. Res., 2010; 2(1): 232-239.

37. Singh, H., Sidhu, S., Chopra, K., Khan, M.U. The novel role of $\beta$-aescin in attenuating $\mathrm{CCl} 4$ - induced hepatotoxicity in rats. Pharm, Biol., 2017; 55(1): 749-757.

38. Huang, D.H., Chen, C., Lin, Y. Antioxidant and antiproliferative activities of water spinach (Ipomoea aquatica Forsk.) constituents. Bot. Bull. Acad. Sin., 2005; 46: 99-106.

39. Sylvie, D.D., Anatole, P.C., Cabral, B.P., Veronique, P.B. Comparison of in vitro antioxidant properties of extracts from three plants used for medical purpose in Cameroon: Acalypha raceosa, Garcinia lucida and Hymenocardia lyrata. Asian. Pac. J. Trop. Biomed., 2014; 4(2): 625-32.

40. Miguel, M.G. Antioxidant activity of medicinal and aromatic plants. A review. Flavour Frager. J., 2010; 25(5): 291-312.

41. Spinella, M. The importance of pharmacological synergy in psychoactive herbal medicines. Altern. Med. Rev., 2002; 7(2):130-137.

Srivastava, S., Lal, V.K., Pant, K.K. Polyherbal formulations based on Indian medicinal plants as antidiabetic phytotherapeutics. Phytopharmacology., 2012; 2(1): 1-15.

Indo Global Journal of Pharmaceutical Sciences( ISSN 2249 1023; CODEN- IGJPAI; NLM ID: 101610675) indexed and abstracted in CrossRef (DOI Enabling), CNKI, UGC CARE Journal List, EMBASE (Elsevier), National Library of Medicine (NLM) Catalog (NCBI), ResearchGate, Publons (Clarivate Analytics), CAS (ACS), Index Copernicus, Google Scholar and many more. For further details, visit http://iglobaljournal.com 